\title{
Adaptor Molecule TRIF in Teleost
}

\author{
Guanjie Wang ${ }^{1,2}$, Guobin $\mathrm{Hu}^{1,2^{*}}$ \\ ${ }^{1}$ College of Marine Life Sciences, Ocean University of China, Qingdao 266003, China \\ ${ }^{2}$ Institute of Evolution \& Marine Biodiversity, Ocean University of China, Qingdao 266003, China \\ Email: huguobin@ouc.edu.cn
}

\begin{abstract}
The immune defense mechanism mainly depends on the recognition and response of innate immune signaling receptors PRRs to PAMPs or DAMPs. TLRs family is an important category in PRRs, stimulatory cytokines and interferon type I (IFN) are produced through TRIF-or MyD88-dependent after TLRs recognition PAMPs or DAMPs, which regulate innate and adaptive immunity responses. TLR3 only relies on the TRIF-dependent pathway for downstream signaling, TLR4 can conduct downstream signaling through both TRIF- and MyD88-dependent pathways. Teleosts TLR3 detects viral and additionally bacterial PAMPs, while TLR3-mediated activation of mammalian immune responses only depends on viral double-stranded RNA intermediates. Teleost TLR4 is suggested to down-regulate TLR signaling and/or to interact with alternative receptors such as b2-integrins, whereas mammalian TLR4 associates with CD14 and MD2 in order to sense LPS. In this review, we will further study the structure of TRIF, the TRIF-dependent signaling pathway, and its function in fish, with emphasis on the TRIF-dependent signaling pathway and different biological activities. The study of TRIF and its role in innate immunity has potential significance for the prevention and treatment of fish diseases.
\end{abstract}

Keywords: TRIF, TRIF-dependent pathway, signal transduction, TLR3 \& 4, teleost

\section{Introduction}

The immune system can be divided into the innate immune system and the adaptive immune system. The innate immune system is the immune defense mechanism in the early stage of the host anti-infection reaction ${ }^{[1]}$. The response of most organisms to pathogens and tissue disorders depends entirely on the innate immune system. This mechanism mainly depends on the recognition and response of innate immune signaling receptors (known as species encoded pattern recognition receptors (PRRs)) to specific microbial components (known as pathogen-associated molecular patterns (PAMPs)) or endogenous molecules produced by injured or dead cells (known as danger-associated molecular patterns (DAMPs)) ${ }^{[2]}$.

PRRS, including Toll-like receptors (TLRs), NOD-like receptors (NLRs), RIG-I-like receptors (RLRs), and C-type lectin receptors (CLRs), are distributed in all subcellular parts of cells, such as the nucleus, cytoplasm, endolysosomal compartment, and cell surface ${ }^{[1]}$. Among them, TLRs have important significance in this field. The TLRs family can be divided into six categories in vertebrates: TLR1 family (TLR1, 2, 6, 10, 15, 17, 18, 25, 27, and 28), TLR3 family, TLR4 family, TLR5 family (TLR5 and TLR5s), TLR7 family (TLR7, 8, and 9) and TLR11 family (TLR11, 12, 13, 14, 16, 19, 20, and 21) ${ }^{[3]}$. So far, 13 type TLRs have been identified in mammals (TLR1-13) ${ }^{[4]}$ and 18 types in teleosts (TLR1-5, 5s, 7-9, $13,14,18-23$, and 25) ${ }^{[5]}$.

Two major adaptor proteins, myeloid differentiation primary response gene 88 (MyD88) and TIR-domain containing adaptor protein inducing IFN- $\beta$ (TRIF) mediate MyD88-and TRIF-dependent signaling pathways, respectively. Almost all TLRs (except TLR3) transmit signals through the MyD88-dependent signaling pathway, while signal transductions of TLR3 and TLR4 are via the TRIF-dependent signaling pathway. Activation of immune response mediated by TLR3 and TLR4 depends on viral double-stranded RNA intermediates and LPS (Ligands are shown in Table 1), respectively. TRIFdependent signaling pathway eventually promotes the activation of the mitogen-activated protein kinase (MAPK) and transcription factors, such as nuclear factor-kappa B (NF-kB), interferon regulatory factors (IRFs), and, activator protein-1 (AP1), inducing the expression of inflammatory cytokine genes and type I interferons (IFNs), modulating innate and adaptive immunity ${ }^{[6]}$. 
Table 1. Descriptions of TLR3 \& 4 in the TRIF-dependent pathway

\begin{tabular}{|c|c|c|c|c|c|c|c|c|}
\hline \multirow{2}{*}{ Receptor } & \multirow{2}{*}{$\begin{array}{l}\text { Subcellular } \\
\text { location }\end{array}$} & \multicolumn{3}{|c|}{ Ligands } & \multirow{2}{*}{$\begin{array}{l}\text { Signaling } \\
\text { adaptor }\end{array}$} & \multirow{2}{*}{$\begin{array}{l}\text { Signaling } \\
\text { Pathway }\end{array}$} & \multirow{2}{*}{$\begin{array}{l}\text { Transcription } \\
\text { factors }\end{array}$} & \multirow{2}{*}{ Effector cytokines } \\
\hline & & Synthetic & PAMPs & DAMPs & & & & \\
\hline TLR3 & $\begin{array}{l}\text { Endosome } \\
\text { membrane }\end{array}$ & Poly I: C & $\begin{array}{c}\text { ssRNA virus; } \\
\text { dsRNA virus; } \\
\text { RSV; } \\
\text { MCMV. }\end{array}$ & mRNA & TRIF & $\begin{array}{l}\text { TRIF- } \\
\text { dependent } \\
\text { pathway }\end{array}$ & $\begin{array}{l}\text { NF-кB; } \\
\text { IRF3, 7; } \\
\text { AP1 }\end{array}$ & $\begin{array}{l}\text { Type I IFNs; } \\
\text { Inflammatory } \\
\text { cytokines }\end{array}$ \\
\hline TLR4 & $\begin{array}{l}\text { Plasma } \\
\text { membrane }\end{array}$ & Pam3CSK4 & $\begin{array}{l}\text { LPS (G-); } \\
\text { HSP72; } \\
\text { S100A8/A9; } \\
\text { MBD2. }\end{array}$ & $\begin{array}{l}\text { Oxidoised } \\
\text { LDL-A } \beta\end{array}$ & TRIF+TRAM & $\begin{array}{l}\text { TRIF- } \\
\text { dependent } \\
\text { pathway }\end{array}$ & $\begin{array}{l}\mathrm{NF}-\kappa \mathrm{B} ; \\
\mathrm{IRF} 3,7 \\
\text { AP1 }\end{array}$ & $\begin{array}{l}\text { Type I IFNs; } \\
\text { Inflammatory } \\
\text { cytokines }\end{array}$ \\
\hline
\end{tabular}

Note: PAMPs, pathogen-associated molecular patterns; DAMPs, damage-associated molecular patterns; Poly I: C, polyinosinic-polycytidylic acid; ssRNA single-stranded RNA; LPS, lipopolysaccharide; G-, Gram-negative bacteria; HSP, heat shock protein; MBD2, Murine beta-defensin 2; LDL-A $\beta$, low-density lipoprotein-amyloid beta; TLR, tolllike receptor; MyD88, myeloid differentiation primary response gene 88; TIRAP, TIR domain-containing adaptor protein; TRIF, TIR-domain contain-ing adaptor protein inducing IFN- $\beta$; TRAM, TRIF-related adaptor molecule; dsRNA, double-stranded RNA; mRNA, messenger RNA; NF-אB, nuclear factor-kappaB; IRF, interferon regulatory factors; IFN, interferons. Reference to previous data ${ }^{[7,8]}$.

According to the records from Fishes of the World, there are about 26,840 species of teleosts, accounting for $96 \%$ of the total number of fishes, close to half of the total amount of all vertebrates, and play an important role in the evolution of species ${ }^{[9]}$. The survival process of fish is always accompanied by a large number of microbial groups in the environment, including protozoa, fungi, bacteria, and viruses. In the evolutionary process of resisting the invasion of complex pathogenic microorganisms, fish have also established a relatively complete set of immune defense system ${ }^{[10]}$. Studies of TRIF and its role in the innate immune will potentially have implications for the prevention and treatment of fish diseases.

\section{TRIF adaptor}

TLR4 could activate NF- $\kappa$ B in the absence of MyD88, which led to the discovery of the TRIF-dependent pathway ${ }^{[11]}$. Then, TRIF was identified from the TLR3 signaling pathway by the yeast two-hybrid experiment and was originally named as TIR-containing adaptor molecule (TICAM)-1 ${ }^{[12]}$. TRIF is directly recruited to TLR3, while the association with TLR4 requires the TRIF-related adaptor molecule (TRAM), also known as TIR domain-containing adaptor molecule-2 $\left(\right.$ TICAM-2) ${ }^{[13]}$.

TRIF adaptor consists of an N-terminal domain (NTD), several tumor necrosis factor receptor-associated factor (TRAF)-binding motifs (TBMs), a TIR domain, and a C-terminal region including the receptor-interacting protein (RIP)binding motif (RHIM) ${ }^{[6]}$. The NTD domain of TRIF may binding to the TIR domain of TRIF or may serve as a sensor domain for an unknown ligand, and their binding can expose the binding sites for TANK-binding kinase-1 (TBK1) ${ }^{[13,14]}$. TRAF2, 3, and 6 bind different TBM sites of TRIF through the TRAF domain ${ }^{[15]}$. TRAF3 plays an important role in the induction of IFN mediated by TRIF. The combination of TRIF with TRAF2 and TRAF6 can accelerate the polyubiquitination of TRIF, while its elimination will strongly inhibit the induction of IFN ${ }^{[16]}$. The TIR-domain of TRIF is essential for interactions with other TIR domains, such as TIR domains of TLR3 and TRAM, and is also involved in TRIF homo-oligomerization ${ }^{[6]}$. The RHIM domain of TRIF can bind the RHIM domains of RIP1 and RIP3. RIP1 mediates TRIF-induced NF- $\kappa$ B activation, while RIP3 negatively regulates this activation by inhibiting the TRIF-RIP1-induced NF$\kappa \mathrm{B}$ pathway ${ }^{[17]}$.

\section{TRIF-dependent pathway}

TLR3 recognizes viral double-stranded RNA intermediates directly ${ }^{[18]}$. In contrast, TLR4 recognizes LPS through the key step in which LPS-binding protein (LBP) mediates the aggregation of LPS to the cell surface and forms a ternary complex with Cluster of differentiation 14 (CD14). This LPS/LBP/CD14 facilitates the transfer of monomer LPS to TLR4 and another co-stimulatory molecule, myeloid differentiation protein 2 (MD2) ${ }^{[19]}$. TRIF adaptor plays an important role in the TRIF-dependent pathway which is peculiar to the TLR3- and TLR4-downstream signaling and recruits TBK1, TRAFs, and RIPs ${ }^{[20]}$. Downstream transcription factors of the TRIF-dependent signaling pathway play an important role in the regulation of immune defense. TRAF3 and nuclear factor- $\kappa \mathrm{B}$ essential modulator (NEMO) recruited I $\mathrm{B}$ kinase (IKK)related kinases TANK-binding kinase-1 (TBK1) and Ikki to phosphorylate IRF3. The phosphorylated IRF3 formed a dimer to induce the expression of type I IFNs ${ }^{[21]}$. TRAF6 recruits kinase RIP1, which interacts with transforming growth factor- $\beta$ 
activated kinase-1 (TAK1) to activate NF-кB and MAPK, inducing the release of inflammatory cytokines, such as tumor necrosis factor-alpha (TNF $\alpha$ ) and interleukin-6 (IL6). RIP1 can also be recruited by E3 ubiquitin-protein ligase (Pellino1) ${ }^{[22]}$. Pellino1 can activate IRF3 by combining with modified electronic auto-regulation factor-1 (DEAF1). The activation of IRF3 was regulated by phosphatidylinositol 5-phosphate (PtdIns5P) ${ }^{[23]}$. The binding of PtdIns5P with IRF3 and TBK1 can promote TBK1 and IRF3 to form complexes, leading to the robust up-regulation of IFNs ${ }^{[24]}$.

TLR signaling is negatively regulated by many molecules through a variety of mechanisms to prevent or terminate the immune response that leads to harmful consequences associated with autoimmune and inflammatory diseases. The activation of the TRIF-dependent pathway was inhibited by TAG and Sterile $\alpha$-and armadillo motif-containing protein (SARM) ${ }^{[25]}$, which binds to TRIF to prevent their binding to TLRs or downstream molecules. TRAF3 activation was inhibited by deubiquitinating enzyme A (DUBA) and SOCS3 ${ }^{[26]}$. TRAF6 is targeted by many inhibitors, such as CYLD, HP, A20 (a cytoplasmic protein), Tripartite motif 38 (TRIM38), TANK, and ubiquitin-specific peptidase 4 (USP4) ${ }^{\text {[27, }}$ ${ }^{28]}$. The activation of TAK1 was inhibited by A20 and TRIM30 $\alpha^{[29]}$. The activation of NF- $\kappa \mathrm{B}$ was inhibited by PDLIM2,

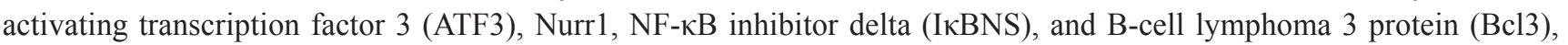
while the activation of IRF3 was inhibited by peptidyl-prolyl cis-trans isomerase NIMA-interacting 1 (Pin1) and RAUL ${ }^{[30]}$ Giovanna $<$ /author $><$ author $>$ Leveque, Gary $<$ /author $><$ author $>$ Line Larivière $<$ /author $><$ author $>$ Laroche, Line $</$ author $><$ author $>$ Malo, Danielle $<$ /author $><$ /authors $><$ /contributors $><$ titles $><$ title $>$ Cloning and Characterization of the Murine Toll-like Receptor 5 (Tlr5.

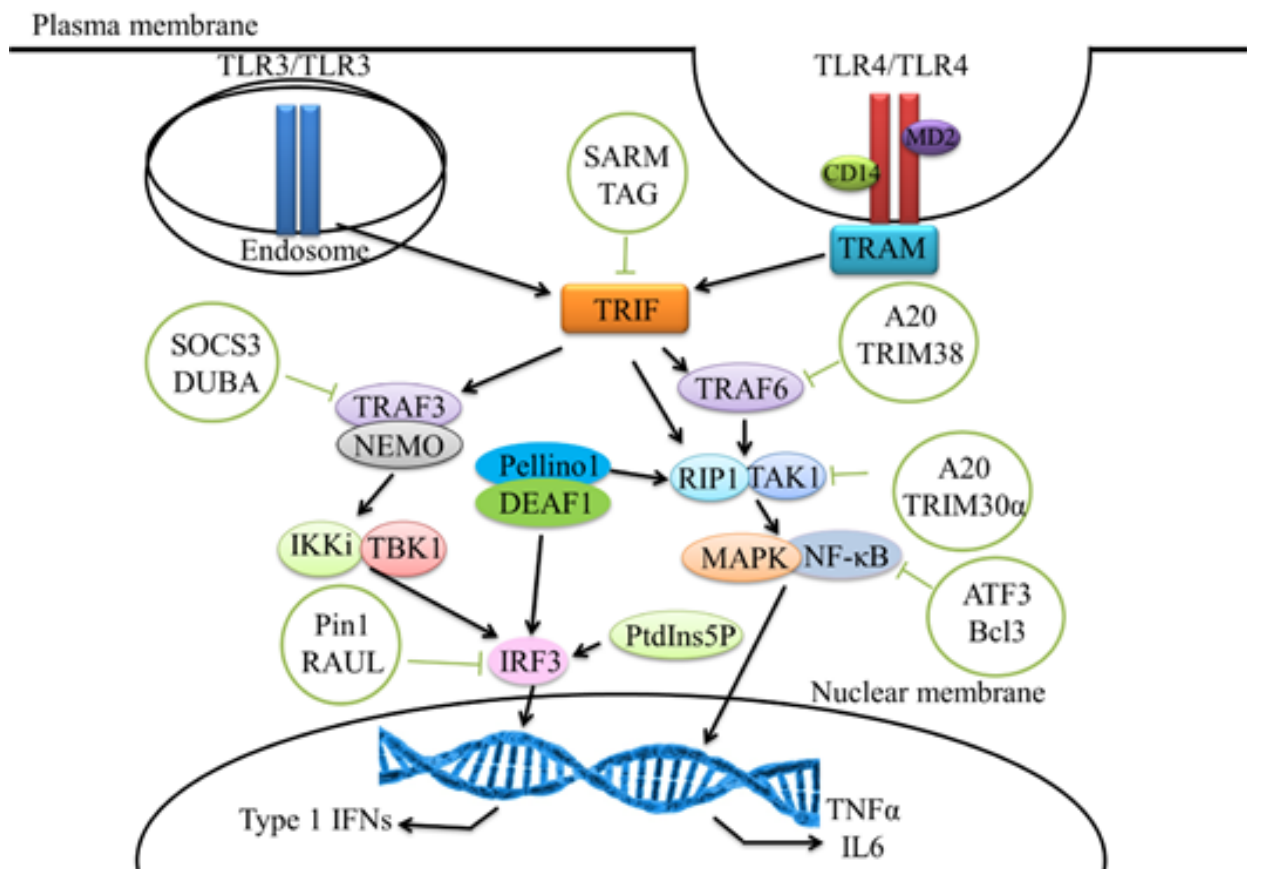

Figure 1. Schematic diagram of TRIF-dependent signal cascade

\section{TRIF in teleost}

The whole-genome duplication (WGD) occurred in the evolutionary process of fish, which led to the production of many new genes in fish, and the immune defense response of fish was significantly different from that of other vertebrates ${ }^{[31]}$. In mammals, TICAM contains two genes, TICAM1 (TRIF) and TICAM2 (TRAM), but there is only a TRIF in fish, which is a counterexample of the hypothesis that "there are more genes in fish" ${ }^{[32]}$. However, there is only a TRIF but no TRAM sequences in both chicken (Gallus gallus) and African frog (Xenopus laevis). The TICAM gene, which is considered to be an ancestor, has been specifically replicated in mammalian lineage ${ }^{[8]}$.

Since the TRIF sequence in the genome of channel catfish (Ictalurus punctatus) was cloned ${ }^{[33]}$, the research of TRIF in fish has been gradually carried out. Later, the structure and expression of the TRIF gene were cloned and analyzed from zebrafish (Danio rerio) ${ }^{[34]}$, grass carp (Ctenopharyngodon idella) ${ }^{[35]}$, orange-spotted grouper (Epinephelus coioides) ${ }^{[36]}$, large yellow croaker (Larimichthys croceared) ${ }^{[37]}$, etc. TRIF transcripts are distributed in all tissues of fish, and the stimulation of Gram-negative bacteria and dsRNA virus can induce the expression of trif ${ }^{[35]}{ }^{[36]}$. 
Three kinds of motifs (gamma IFN activated sequence sites, IFN-stimulated response element motifs, and GAAA/ TTTC motifs) which are the characteristics of genes responsive to both IFN-I and IFN-II were identified in the trif sequence of grass carp ${ }^{[35]}$. The TRIF protein of zebrafish, anchoring on Golgi apparatus, doesn't contain any T6BMs,

\section{TRIF-dependent pathway in teleost}

Different from mammals, TLR3 detects viral and additionally bacterial PAMPs in teleosts. Poly I: C, a synthetic inosine polymer resembling RNA, up-regulated tlr3 gene expression in kidney leucocytes of rainbow trout (Oncorhynchus mykiss), in macrophages of rainbow trout, and in gills, head kidney, spleen, and muscle of turbot (Scophthalmus maximus) ${ }^{[38,39]}$. Turbot reddish body iridovirus (TRBIV) also up-regulated the expression of TLR3 in turbot ${ }^{[39]}$. After infection with Gramnegative Edwardsiella tarda and Edwardsiella ictulari, the expression of TLR3 mRNA increased in channel catfish and blue channel-blue backcross hybrid, respectively ${ }^{[40,41]}$. During PAMPs recognition in the endosome, TLR3 interacts TRIFdependently with TRIF. Zebrafish TRIF recruit two typical downstream factors RIP1 and TBK $1^{[17]}{ }^{[42]}$ to activate NF-kB and activate IFN- $\beta$ in an IRF3/7 independent manner ${ }^{[34]}$, and large yellow croaker traf 3 enhances TRIF-dependent pathway via NF-KB and IRF3 activation ${ }^{[43]}$. And then, leading the expression of TRIF and induce the activation of downstream signaling pathways.

Table 2. Descriptions of TLR3 in teleosts TRIF-dependent pathway

\begin{tabular}{|c|c|c|c|c|c|c|c|}
\hline Receptor & $\begin{array}{l}\text { Subcellular } \\
\text { location }\end{array}$ & \multicolumn{2}{|c|}{ Ligands } & $\begin{array}{l}\text { Signaling } \\
\text { adaptor }\end{array}$ & $\begin{array}{l}\text { Signaling } \\
\text { Pathway }\end{array}$ & $\begin{array}{l}\text { Transcription } \\
\text { factors }\end{array}$ & $\begin{array}{l}\text { Effector } \\
\text { cytokines }\end{array}$ \\
\hline TLR3 & $\begin{array}{l}\text { Endosome } \\
\text { membrane }\end{array}$ & $\begin{array}{c}\text { Edwardsiella } \\
\text { ictaluri; } \\
\text { Edwardsiella } \\
\text { tarda. }\end{array}$ & $\begin{array}{l}\text { GCRV; } \\
\text { SHRV; } \\
\text { IHNV; } \\
\text { Poly I: C. }\end{array}$ & TRIF & $\begin{array}{l}\text { TRIF-dependent } \\
\text { pathway }\end{array}$ & $\begin{array}{l}\text { NF-кB; } \\
\text { IFN- } \beta \text {. }\end{array}$ & $\begin{array}{c}\text { MX protein } \\
\text { GIG; } \\
\text { IL-1 } \beta\end{array}$ \\
\hline
\end{tabular}

Note: GCRV, Cteno-pharyngodon idella reovirus; SHRV, Snakehead Rhabdovirus; IHNV, haematopoietic necrosis virus; Poly I:C, polyinosinic-polycytidylic acid; NF- $\mathrm{kB}$, nuclear factor-kappaB; IFN, interferons; GIG, G protein beta subunit; IL, Interleukin.

Unlike mammals, fish are usually resistant to the toxic effects of LPS, for example, the tolerance of Indian major carp (Labeo rohita) to LPS is as high as $20 \mathrm{EU}$ per fish ${ }^{[44]}$. Although two TLR4 genes were found in zebrafish genome, no TLR4 gene was detected from genome sequences in fugu (Takifugu rubripes), pufferfish (Tetraodon nigroviridis), and sticklebacks (Gasterosteus aculeatus) ${ }^{[10]}$. Neither CD14 nor MD2 has been found in teleosts so far. Thus, the cognition mechanism of LPS in fish is fundamentally different from that of mammals, which is of great significance for sensing of LPS structure that different from terrestrial animal pathogens ${ }^{[45]}$. No induction of TLR4 has been observed in Mycobacterium marinum-infected zebrafish, and receptors b2-integrins was expressed on mononuclear phagocytes of rainbow trout after stimulation with a high concentration of LPS ${ }^{[46,47]}$. This phenomenon may prove the hypothesis that fishes may recognize LPS through alternative factors such as b2-integrins. The expression of trif gene was downregulated after infection with Edwardsiella ictaluri in the spleen of blue catfish (Ictalurus furcatus). In contrast, bacterial infection-induced TLR4 expression in the rare minnow (Gobiocypris rarus) and orange-spotted grouper ${ }^{[36,4]}$. Therefore, the difference of trif expression in different teleosts induced by LPS seems to be related to fish species. Besides, there is another hypothesis that fish TLR4 plays a negative role in LPS signal transduction in the MyD88-dependent TLR pathway, and only higher vertebrates have TLR4-dependent immune activation at very low doses of LPS ${ }^{[48]}$. 


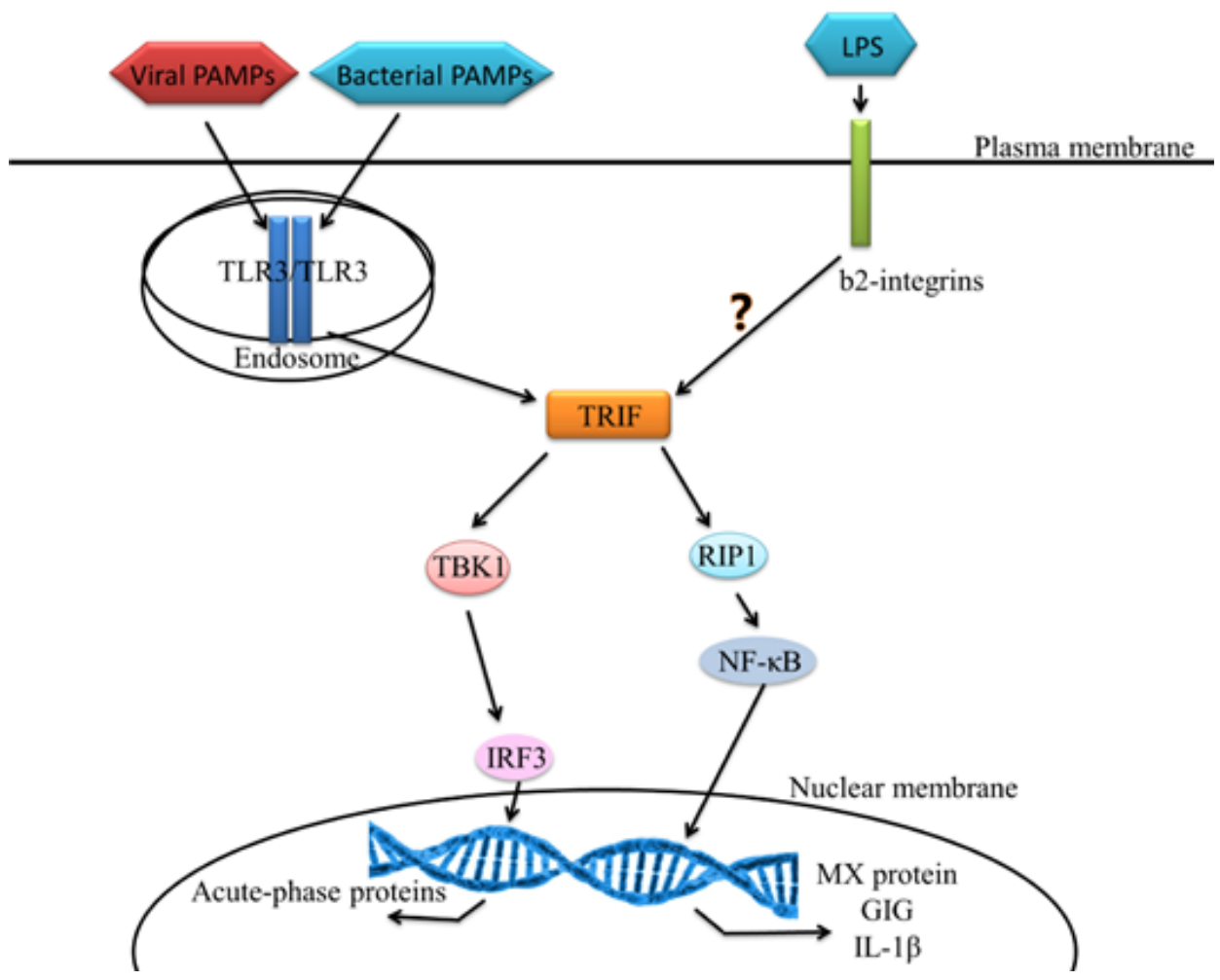

Figure 2. Schematic diagram of fish TRIF-dependent signal cascade

\section{Conclusion}

The biological function and signal transduction mechanism of TRIF in fish is still a new field and plays an important role in TLRs signaling pathway. Although there are still many obstacles, TRIF seems to be a very interesting, attractive, and exploitable target for the treatment of infectious diseases. At present, the main task is to identify downstream molecules among TRIF-dependent signaling pathways, which will help us understand the disease-resistance mechanism of fish, and develop new adjuvants and/or more effective vaccines and therapies. Besides, the combination of TRIF molecular research and auxiliary molecules in fish may bring new insights into the function of fish TRIF.

\section{Acknowledgments}

This work was supported by the Fundamental Research Funds for the Central Universities (201822025, 201762003) and Shandong Provincial Natural Science Foundation (ZR2019MC051).

\section{References}

[1] Takeuchi O, Akira S. Pattern recognition receptors and inflammation. Cell. 2010; 140(6): 805-820.

[2] Kvarnhammar AM, Cardell LO. Pattern-recognition receptors in human eosinophils. Immunology. 2012; 136(1): 1120.

[3] Roach JC, Gustavo G, Lee R, Amardeep K, Purcell MK, Smith KD, et al. The evolution of vertebrate Toll-like receptors. Proc Natl Acad Sci U S A. 2005; 102(27): 9577-9582.

[4] Bruce B. Inferences, questions and possibilities in Toll-like receptor signalling. Nature. 2004; 430(6996): 257-263.

[5] Boudinot P, Zou J, Ota T, Buonocore F, Scapigliati G, Canapa A, et al. A tetrapod-like repertoire of innate immune receptors and effectors for coelacanths. J Exp Zool B Mol Dev Evol. 2014; 322(6): 415-437.

[6] Kumeta H, Sakakibara H, Enokizono Y, Ogura K, Horiuchi M, Matsumoto M, et al. The N-terminal domain of TIR domain-containing adaptor molecule-1, TICAM-1. J Biomol NMR. 2014; 58(3): 227-230.

[7] O'Neill LAJ, Golenbock D, Bowie AG. The history of Toll-like receptors - Redefining innate immunity. Nature Reviews Immunology. 2013; 13(6): 453-460.

[8] Saavedra V, Moghaddas F, Latz E, Masters SL. Pattern Recognition Receptors in Autoinflammation//Philip J. H, Ron- 
ald M. L, Simon A. Textbook of Autoinflammation. 2019.

[9] Joseph S Nelson. Fishes of the World. Fourth Edition. New Jersey: Wiley; 2006.

[10] Tanekhy M. The role of Toll-like Receptors in innate immunity and infectious diseases of teleost. Aquacult Res. 2016; 47(5): 1369-1391.

[11] Horng T, Barton GM, Medzhitov R. TIRAP: an adapter molecule in the Toll signaling pathway. Nat Immunol. 2001; 2(9): 835-841.

[12] Oshiumi H, Matsumoto M, Funami K, Akazawa T, Seya T. TICAM-1, an adaptor molecule that participates in Tolllike receptor 3-mediated interferon-beta induction. Nat Immunol. 2003; 4(2): 161-167.

[13] Ullah MO, Ve T, Mangan M, et al. The TLR signalling adaptor TRIF/TICAM-1 has an N-terminal helical domain with structural similarity to IFIT proteins. Acta Crystallogr D Biol Crystallogr. 2013; 69(Pt 12): 2420-2430.

[14] Tatematsu M, Ishii A, Oshiumi H, et al. A molecular mechanism for Toll-IL-1 receptor domain-containing adaptor molecule-1-mediated IRF-3 activation. J Biol Chem. 2010; 285(26): 20128-20136.

[15] Sato S, Sugiyama M, Yamamoto M, Watanabe Y, Kawai T, Takeda K, et al. Toll/IL-1 Receptor Domain-Containing Adaptor Inducing IFN- $\beta$ (TRIF) Associates with TNF Receptor-Associated Factor 6 and TANK-Binding Kinase 1, and Activates Two Distinct Transcription Factors, NF-кB and IFN-Regulatory Factor-3, in the Toll-Like Receptor Signaling. J Immunol. 2003; 171(8): 4304-4310.

[16] Sasai M, Tatematsu M, Oshiumi H, Funami K, Matsumoto M, Hatakeyama S, et al. Direct binding of TRAF2 and TRAF6 to TICAM-1/TRIF daptor participates in activation of the Toll-like receptor 3/4 pathway. Mol Immunol. 2010; 47(6): 1283-1291.

[17] Meylan E, Burns K, Hofmann K, Blancheteau V, Martinon F, Kelliher M, et al. RIP1 is an essential mediator of Tolllike receptor 3-induced NF- $\kappa$ B activation. Nat Immunol. 2004; 5(5): 503-507.

[18] Vercammen E, Staal J, Beyaert R. Sensing of viral infection and activation of innate immunity by toll-like receptor 3. Clin Microbiol Rev. 2008; 21(1): 13-25.

[19] Dauphinee SM, Karsan A. Lipopolysaccharide signaling in endothelial cells. Lab Invest. 2006; 86(1): 9-22.

[20] Takeda K, Akira S. TLR signaling pathways. Semin Immunol. 2004; 16(1): 3-9.

[21] Kawai T, Akira S. The role of pattern-recognition receptors in innate immunity: update on Toll-like receptors. Nat Immunol. 2010; 11(5): 373-384.

[22] Chang M, Jin W, Sun SC. Peli1 facilitates TRIF-dependent Toll-like receptor signaling and proinflammatory cytokine production. Nat Immunol. 2009; 10(10): 1089-1095.

[23] Kawasaki T, Takemura N, Standley DM, Akira S, Kawai T. The second messenger phosphatidylinositol-5-phosphate facilitates antiviral innate immune signaling. Cell Host Microbe. 2013; 14(2): 148-158.

[24] Kawasaki T, Kawai T. Toll-like receptor signaling pathways. Front Immunol. 2014; 5: 461.

[25] Wright, S. D. Toll, A New Piece in the Puzzle of Innate Immunity. The Journal of experimental medicine. 1999; 189(4): 605-609.

[26] Da SC, J., Ulevitch RJ. MD-2 and TLR4 N-Linked Glycosylations Are Important for a Functional Lipopolysaccharide Receptor. J Biol Chem. 2002; 277(3): 1845-1854.

[27] Visintin A, Mazzoni A, Spitzer JA, Segal DM. Secreted MD-2 is a large polymeric protein that efficiently confers lipopolysaccharide sensitivity to Toll-like receptor 4. Proceedings of the National Academy of ences. 2001; 98(21): 12156-12161.

[28] Lek M, Karczewski K, Minikel E, et al. Analysis of protein-coding genetic variation in 60,706 humans. Nature. 2016; 536(7616): 285-291.

[29] Arbour NC, Lorenz E, Schutte BC, Zabner J, Kline JN, Jones M, et al. TLR4 mutations are associated with endotoxin hyporesponsiveness in humans. Nat Genet. 2000; 25(2):187-191.

[30] Sebastiani G, Leveque G, Larivière L, Laroche L, Malo D. Cloning and Characterization of the Murine Toll-like Receptor 5 (Tlr5) Gene: Sequence and mRNA Expression Studies in Salmonella-Susceptible MOLF/Ei Mice. Genomics. 2000; 64(3): 230-240.

[31] Volff JN. Genome evolution and biodiversity in teleost fish. Heredity (Edinb). 2005; 94(3): 280-294.

[32] Wittbrodt J, Meyer A, Schartl M. More genes in fish? Bioessays. 1998; 20(6): 511-515.

[33] Baoprasertkul P, Peatman E, Somridhivej B, Liu Z. Toll-like receptor 3 and TICAM genes in catfish: species-specific expression profiles following infection with Edwardsiella ictaluri. Immunogenetics. 2006; 58(10): 817-830.

[34] Fan S, Chen S, Liu Y, Lin Y, Liu H, Guo L, et al. Zebrafish TRIF, a Golgi-localized protein, participates in IFN induction and NF- $\kappa$ B activation. J Immunol. 2008; 180(8): 5373-5383.

[35] Yang C, Li Q, Su J, Chen X, Wang Y, Peng L. Identification and functional characterizations of a novel TRIF gene from grass carp (Ctenopharyngodon idella). Dev Comp Immunol. 2013; 41(2): 222-229.

[36] Wei J, Zhang X, Zang S, Qin Q. Expression and functional characterization of TRIF in orange-spotted grouper (Epinephelus coioides). Fish Shellfish Immunol. 2017; 71: 295-304. 
[37] Zou PF, Shen JJ, Li Y, Yan Q, Zou ZH, Zhang ZP, et al. Molecular cloning and functional characterization of TRIF in large yellow croaker Larimichthys crocea. Fish Shellfish Immunol. 2019; 91: 108-121.

[38] Chiou PP, Lin CM, Bols NC, Chen TT. Characterization of virus/double-stranded RNA-dependent induction of antimicrobial peptide hepcidin in trout macrophages. Dev Comp Immunol. 2007; 31(12): 1297-1309.

[39] Hu GB, Li XP, Liu DH, Liu QM, Zhang SC. A toll-like receptor 3 homologue that is up-regulated by poly I:C and DNA virus in turbot Scophthalmus maximus. J Fish Biol. 2015; 86(2): 431-447.

[40] Bilodeau AL, Peterson BC, Bosworth BG. Response of toll-like receptors, lysozyme, and IGF-I in back-cross hybrid (F1 male (blue x channel) $x$ female channel) catfish challenged with virulent Edwardsiella ictaluri. Fish Shellfish Immunol. 2006; 20(1): 29-39.

[41] Bilodeau AL, Waldbieser GC. Activation of TLR3 and TLR5 in channel catfish exposed to virulent Edwardsiella ictaluri. Dev Comp Immunol. 2005; 29(8): 713-721.

[42] Chau TL, Gioia R, Gatot JS, Patrascu F, Carpentier I, Chapelle JP, et al. Are the IKKs and IKK-related kinases TBK1 and IKK-epsilon similarly activated? Trends Biochem Sci. 2008; 33(4): 171-180.

[43] Zou PF, Shen JJ, Li Y, Zhang ZP, Wang YL. TRAF3 enhances TRIF-mediated signaling via NF-kappaB and IRF3 activation in large yellow croaker Larimichthys crocea. Fish Shellfish Immunol. 2020; 97: 114-124.

[44] Nayak SK, Swain P, Nanda PK, Dash S, Shukla S, Meher PK, et al. Effect of endotoxin on the immunity of Indian major carp, Labeo rohita. Fish Shellfish Immunol. 2008; 24(4): 394-399.

[45] Purcell MK, Smith KD, Hood L, Winton JR, Roach JC. Conservation of Toll-Like Receptor Signaling Pathways in Teleost Fish. Comparative biochemistry and physiology Part D, Genomics \& proteomics. 2006; 1(1): 77-88.

[46] Meijer AH, Gabby Krens SF, Medina Rodriguez IA, He S, Bitter W, Ewa Snaar-Jagalska B, et al. Expression analysis of the Toll-like receptor and TIR domain adaptor families of zebrafish. Mol Immunol. 2004; 40(11): 773-783.

[47] Su J, Yang C, Xiong F, Wang Y, Zhu Z. Toll-like receptor 4 signaling pathway can be triggered by grass carp reovirus and Aeromonas hydrophila infection in rare minnow Gobiocypris rarus. Fish Shellfish Immunol. 2009; 27(1): 33-39.

[48] Sepulcre MP, Alcaraz-Perez F, Lopez-Munoz A, Roca FJ, Meseguer J, Cayuela ML, et al. Evolution of lipopolysaccharide (LPS) recognition and signaling: fish TLR4 does not recognize LPS and negatively regulates NF-kappaB activation. J Immunol. 2009; 182(4): 1836-1845. 